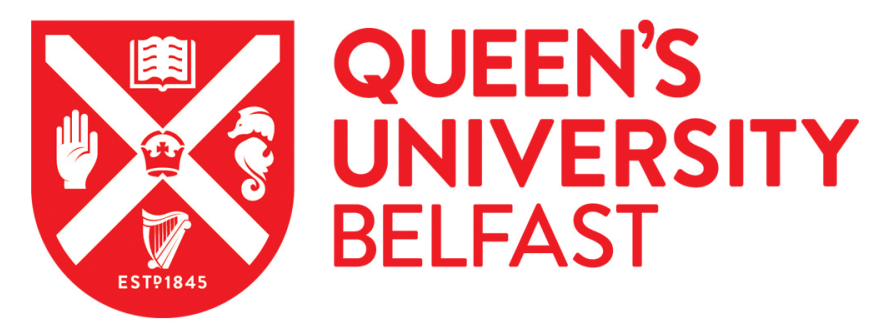

\title{
Modeling target bulk heating resulting from ultra-intense short pulse laser irradiation of solid density targets
}

Antici, P., Gremillet, L., Grismayer, T., Mora, P., Audebert, P., Borghesi, M., Cecchetti, C. A., Mančic, A., \& Fuchs, J. (2013). Modeling target bulk heating resulting from ultra-intense short pulse laser irradiation of solid density targets. Physics of Plasmas, 20(12), 123116-1 - 123116-8. [123116]. https://doi.org/10.1063/1.4833618

Published in:

Physics of Plasmas

Document Version:

Publisher's PDF, also known as Version of record

Queen's University Belfast - Research Portal:

Link to publication record in Queen's University Belfast Research Portal

\section{General rights}

Copyright for the publications made accessible via the Queen's University Belfast Research Portal is retained by the author(s) and / or other copyright owners and it is a condition of accessing these publications that users recognise and abide by the legal requirements associated with these rights.

Take down policy

The Research Portal is Queen's institutional repository that provides access to Queen's research output. Every effort has been made to ensure that content in the Research Portal does not infringe any person's rights, or applicable UK laws. If you discover content in the Research Portal that you believe breaches copyright or violates any law, please contact openaccess@qub.ac.uk. 


\section{AIP $\left.\right|_{\text {Physics of }} ^{\text {Plo }}$ \\ Plasmas}

\section{Modeling target bulk heating resulting from ultra-intense short pulse laser irradiation of solid density targets}

P. Antici, L. Gremillet, T. Grismayer, P. Mora, P. Audebert, M. Borghesi, C. A. Cecchetti, A. Manic, and J. Fuchs

Citation: Physics of Plasmas (1994-present) 20, 123116 (2013); doi: 10.1063/1.4833618

View online: http://dx.doi.org/10.1063/1.4833618

View Table of Contents: http://scitation.aip.org/content/aip/journal/pop/20/12?ver=pdfcov

Published by the AIP Publishing

\section{Articles you may be interested in}

Energy transport and isochoric heating of a low-Z, reduced-mass target irradiated with a high intensity laser pulse

Phys. Plasmas 18, 022702 (2011); 10.1063/1.3551591

Terahertz radiation from a wire target irradiated by an ultra-intense laser pulse

Phys. Plasmas 14, 054505 (2007); 10.1063/1.2734945

Ion Generation via Interaction between Intense Ultrashort Laser Pulse and Solid Target for Application to

Cancer Therapy

AIP Conf. Proc. 647, 265 (2002); 10.1063/1.1524880

Neutron emission from a deuterated solid target irradiated by an ultraintense laser pulse

Phys. Plasmas 8, 1011 (2001); 10.1063/1.1344919

Filamentation of ultrashort pulse laser beams resulting from their propagation over long distances in air

Phys. Plasmas 6, 1615 (1999); 10.1063/1.873715

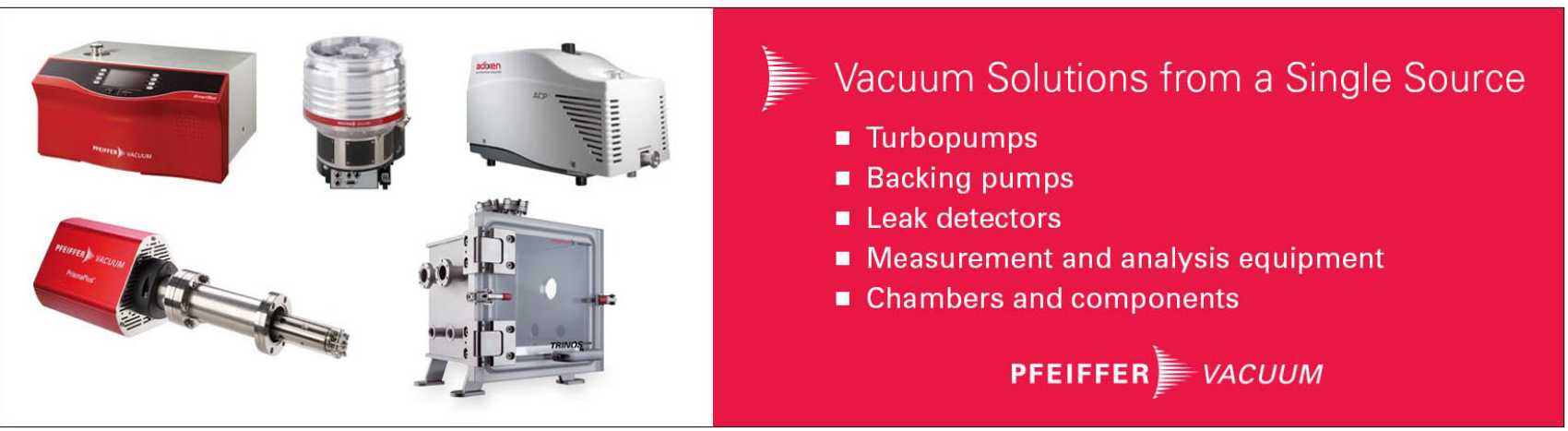




\title{
Modeling target bulk heating resulting from ultra-intense short pulse laser irradiation of solid density targets
}

\author{
P. Antici, ${ }^{1,2,3,4, a)}$ L. Gremillet, ${ }^{5}$ T. Grismayer, ${ }^{6}$ P. Mora, ${ }^{7}$ P. Audebert, ${ }^{4}$ M. Borghesi, ${ }^{8}$ \\ C. A. Cecchetti, ${ }^{8}$ A. Mančic, ${ }^{4}$ and J. Fuchs ${ }^{4}$ \\ ${ }^{1}$ Dipartimento SBAI, Università di Roma “La Sapienza," Via Scarpa 14-16, 00161 Roma, Italy \\ ${ }^{2}$ INRS-EMT, Varennes, Québec, Canada \\ ${ }^{3}$ Istituto Nazionale di Fisica Nucleare, Via E. Fermi, 40-00044 Frascati, Italy \\ ${ }^{4}$ LULI, École Polytechnique, CNRS, CEA, UPMC, route de Saclay, 91128 Palaiseau, France \\ ${ }^{5}$ CEA, DAM, DIF, F-91297 Arpajon, France \\ ${ }^{6}$ GoLP/Instituto de Plasmas e Fusão Nuclear-Laboratório Associado, Instituto Superior Técnico, \\ 1049-001 Lisboa, Portugal \\ ${ }^{7}$ Centre de Physique Théorique, École Polytechnique, CNRS, 91128 Palaiseau, France \\ ${ }^{8}$ School of Mathematics and Physics, The Queen's University, Belfast, United Kingdom
}

(Received 27 June 2013; accepted 28 October 2013; published online 27 December 2013)

Isochoric heating of solid-density matter up to a few tens of $\mathrm{eV}$ is of interest for investigating astrophysical or inertial fusion scenarios. Such ultra-fast heating can be achieved via the energy deposition of short-pulse laser generated electrons. Here, we report on experimental measurements of this process by means of time- and space-resolved optical interferometry. Our results are found in reasonable agreement with a simple numerical model of fast electron-induced heating. (C) 2013 AIP Publishing LLC. [http://dx.doi.org/10.1063/1.4833618]

\section{INTRODUCTION}

Over the past decade, significant effort has been dedicated to particle acceleration by ultra-intense lasers $\left(I>10^{18} \mathrm{~W} / \mathrm{cm}^{2}\right)$. These high-energy, short-pulse, compact particle (or radiation) sources may be useful for a number of applications, ranging from inertial confinement fusion, ${ }^{1-3}$ radiography of dense material, ${ }^{4}$ generating compact particlemicro-lenses, ${ }^{5}$ accelerator physics, ${ }^{6,7}$ to the generation of warm dense matter (WDM) states $^{8-11}$ Regarding the latter, the capability of laser-generated fast electrons to isochorically heat solid samples has been recently demonstrated. ${ }^{12}$

The energetic electrons produced during high-intensity laser-matter interaction deposit their energy into the target through a variety of collisional and collective processes. This energy dissipation takes place over a short time scale with respect to the hydrodynamic expansion of the target. The fast electrons can be split into two groups. The highest-energy electrons $(>\mathrm{MeV})$ will propagate through the target with little energy transfer. By contrast, the moderate-energy electrons (0.1-1 MeV), of much higher density, will be affected by the fields set up inside the target and at its boundaries. ${ }^{13}$ For typical laser and target parameters, the maximum bulk electron heating evidently increases with the fast electron current density.

Aside from experimental evidence suggesting that the hot electrons give rise to large longitudinal ${ }^{14}$ and transverse ${ }^{15}$ temperature gradients, there is still a need of quantitative modeling of the underlying physics. Indeed, the standard simulation tools used to this goal either (i) treat kinetically all plasma species (as in PIC codes), but commonly overestimate the target heating due to improper equations of state (fixedionization perfect gases are usually assumed), reduced geometry (generally 2D Cartesian) and some level of numerical

\footnotetext{
${ }^{\text {a)} E l e c t r o n i c ~ m a i l: ~ p a t r i z i o . a n t i c i @ p o l y t e c h n i q u e . e d u . ~}$
}

heating; or (ii) combine kinetic (for the fast electrons) and fluid (for the bulk plasma) descriptions, but at the cost of an ad hoc characterization of the fast electron source and a somewhat artificial discrimination between fast and bulk particles. These difficulties motivate highly-resolved experimental measurements that can serve to benchmark numerical models of fast electron generation and transport.

Up to now, the fast electron-induced heating was diagnosed either from the target thermal emission ${ }^{12,16}$ or through $\mathrm{X}$-ray spectroscopy. ${ }^{17-19}$ Since it is usually performed in a frequency window that is off the peak of the Planckian distribution, the first method has often a poor resolution over the typical temperature range of current experiments $(\sim 10-100 \mathrm{eV})$. By contrast, it allows spatial and temporal resolutions, though limited to a few tens of $\mu \mathrm{m}$ and ps. The second technique usually permits more accurate temperature measurements, yet with a degraded (if any) spatial resolution. To overcome these limitations, we have recently developed a novel time- and space-resolved optical interferometry (TASRI) technique (described in detail in Ref. 20), which enables the simultaneous determination of hot electron density and temperature $\left(n_{h}, T_{h}\right)$ and bulk (cold) electron temperature $\left(T_{c}\right)$ at the target rear surface. ${ }^{21}$

In this paper, we will show that the bulk electron temperatures inferred from the TASRI data are correctly reproduced by a simple (0-D) three-component (hot electrons, bulk electrons, and ions) heating model. In addition, we will show that the effective hot electron temperature (i.e., that determining the plasma expansion) is weakly sensitive to the laser intensity under the conditions considered in our experiment.

\section{EXPERIMENTAL SETUP AND DATA ACQUISITION}

The experiment was performed using the 100 TW laser at the Laboratoire pour l'Utilisation des Lasers Intenses 
(LULI) working in the chirped pulse amplification (CPA) mode. Its set-up is shown in Figure 1. The wavelength $\left(\lambda_{0}\right)$ of the laser light is $1.057 \mu \mathrm{m}$, and the pulse duration was varied from $\tau=320$ fs to $\tau=5 \mathrm{ps}$, as measured after compression and before focusing. Focusing of the main interaction laser was achieved using a $\mathrm{f} / 3$ off-axis parabola, and targets positioned at focus were irradiated at normal incidence. Dynamic wave front correction was applied before every shot. ${ }^{22}$ For the TASRI diagnostic, a probe beam was used at the same wavelength as the main beam (i.e., $\lambda_{\mathrm{p}}=1.057 \mu \mathrm{m}$ ). The probe beam is a pick-off from the main beam (see Figure 1) with diameter of about $16 \mathrm{~mm}$, energy of about $100 \mathrm{~mJ}$, linearly chirped to about $50 \mathrm{ps}$, and incident on target with $\theta=45^{\circ}$. With a micrometric timeslide it was possible to change the delay between the main beam and the probe beam with a precision of $<1 \mathrm{ps}$. We used aluminum targets with thickness 25,14 , and $9.4 \mu \mathrm{m}$ and very high quality reflectivity as needed for the TASRI diagnostic. As shown in Figure 1, the image of the target surface, illuminated and reflected by the probe beam, was collected by a lens and sent to the TASRI diagnostic. The interaction laser energy $(\sim 30 \mathrm{~J})$ could be modulated using different attenuating optical densities (OD), namely $\mathrm{OD}=0.3$ (to divide by a factor 2) and $\mathrm{OD}=0.6$ (to divide by a factor 4 ), thus generating various on-target intensities.

The TASRI diagnostic allows us to obtain phase maps of the reflected probe beam on the target rear surface. The experimental data are compared to synthetic phase maps obtained by simulating the phase-shift of a probe beam reflected off the expanding plasma cloud. The target expansion is simulated using the 1-D electrostatic code described in Ref. 31, which considers kinetic ions and Boltzmann-distributed (hot and cold) electrons. This simulation requires, as input, the initial temperature and density of the three plasma species. The total phase shift, $\varphi$, of the probe beam defined as

$$
\varphi=2 \int_{z_{c}}^{Z} k d l=2 \int_{z_{c}}^{Z} \frac{\omega}{c} \sqrt{\varepsilon} d l
$$

is calculated along its forward and return path from a far reference point, $Z$, located in the vacuum up to the reflection point, $z_{c}$. Here, $\omega$ is the laser frequency, $c$ is the velocity of light, and $\epsilon$ is the dielectric constant. In the case of an $s$-polarized beam propagating at an angle $\theta$ with respect to the target normal, reflection occurs at the density $n_{r}=n_{c}\left(1-\sin ^{2} \theta\right)$, where $n_{c}$ is the critical density at the laser frequency $\omega$. The dielectric constant is given by

$$
\varepsilon=1-\frac{\omega^{2}{ }_{p e}}{\omega^{2}\left(1-i \frac{\nu}{\omega}\right)}=1-\frac{n_{e}}{n_{c}\left(1-i \frac{\nu}{\omega}\right)},
$$

with $\nu$ the electron collision frequency, $\omega_{p e}$ the electronic plasma frequency, $n_{e}$ the electron density and $i$ the imaginary unit. Note that Eq. (2) simplifies without collisions to

$$
\varepsilon=1-\frac{n_{e}}{n_{c}} .
$$

As the probe beam samples both the fast-expanding hot electron cloud and the slower-moving bulk plasma, one can infer the hot electron and plasma properties (density, temperature, or mean energy) with high spatial ( $\sim 6 \mu \mathrm{m}$ in the radial direction) and temporal ( $\sim 4 \mathrm{ps})$ resolution. ${ }^{18-20}$ To do so, the density $n_{h}$ and temperature $T_{h}$ of the hot electron source, as well as the bulk electron temperature $T_{c}$ (and therefore the ionization degree of the target ions), ${ }^{23}$ are adjusted so that the simulated phase maps best fit the measured phase maps. Note that the thus inferred hot and bulk electron parameters correspond to effective values, i.e., those determining the

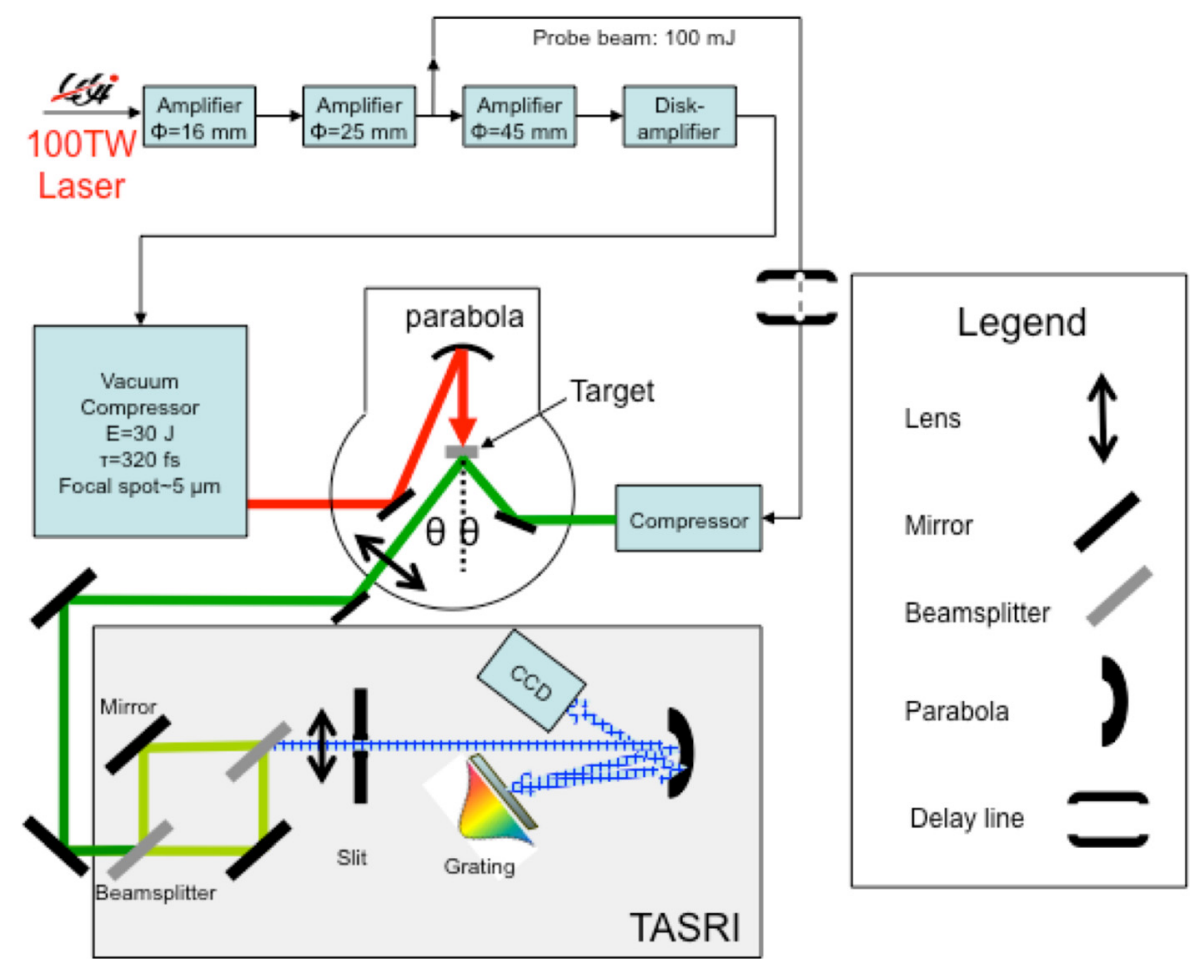

FIG. 1. Experimental setup showing the main and TASRI beam and the interferometric diagnostic (in the gray shaded box). 
TABLE I. $\mathrm{T}_{\mathrm{h}}$ values $(\mathrm{MeV})$ for different target thicknesses $(\mu \mathrm{m})$, pulse durations, and laser intensities $\left(\mathrm{W} / \mathrm{cm}^{2}\right)$. Error bars for the measured temperatures are $0.2 \mathrm{MeV}$.

\begin{tabular}{|c|c|c|c|c|}
\hline \multirow[b]{3}{*}{$\begin{array}{l}\text { Thickness } \\
(\mu \mathrm{m})\end{array}$} & \multicolumn{4}{|c|}{ Pulse duration } \\
\hline & \multicolumn{2}{|c|}{$320 \mathrm{fs}$} & \multicolumn{2}{|c|}{$5 \mathrm{ps}$} \\
\hline & $\begin{array}{l}\text { Intensity } \\
\left(\mathrm{W} / \mathrm{cm}^{2}\right)\end{array}$ & $\begin{array}{l}\mathrm{T}_{\mathrm{h}} \text { rear } \\
(\mathrm{MeV})\end{array}$ & $\begin{array}{l}\text { Intensity } \\
\left(\mathrm{W} / \mathrm{cm}^{2}\right)\end{array}$ & $\begin{array}{l}\mathrm{T}_{\mathrm{h}} \text { rear } \\
(\mathrm{MeV})\end{array}$ \\
\hline 9.4 & $5.00 \mathrm{E}+19$ & 0.85 & & \\
\hline 14 & $5.00 \mathrm{E}+19$ & 0.65 & & \\
\hline 25 & $5.00 \mathrm{E}+19$ & 0.45 & $3.20 \mathrm{E}+18$ & 0.45 \\
\hline 25 & $2.50 \mathrm{E}+19$ & 0.45 & $1.60 \mathrm{E}+18$ & 0.45 \\
\hline 25 & $1.25 \mathrm{E}+19$ & not detected & $8.00 \mathrm{E}+17$ & not detected \\
\hline
\end{tabular}

observed rear-side plasma dynamics. Spatial resolution is obtained by repeating the above procedure at various radial locations, within the assumption that the plasma expansion mostly occurs along the target normal as a function of the local hot electron and plasma parameters (see Refs. 19 and 20).

\section{RESULTS}

Table I summarizes the different laser and target conditions investigated in the experiment. First, a $25 \mu \mathrm{m}$ thick Al target was irradiated by a constant-duration, 320 fs laser pulse with varying laser intensity. Second, the same target was irradiated by a lengthened 5 ps laser pulse. Finally, two Al targets of thicknesses 9.4 and $14 \mu \mathrm{m}$ were shot at maximum intensity $\left(I \sim 5 \times 10^{19} \mathrm{~W} / \mathrm{cm}^{2}\right)$. Table $\mathrm{I}$ also reports the average $T_{h}$ value experimentally inferred in each case. The corresponding spatial profiles of $n_{h}$ and $T_{c}$ are plotted in Figures 2-4. Note that the results of Figure 4 have already been discussed in Ref. 21 and are reported in this manuscript for completeness.

For a $25 \mu \mathrm{m}$ target thickness and a $5 \mathrm{ps}$ pulse, Figure 2(a) shows a bell-shaped $n_{h}$ profile, in agreement with the results of Ref. 4. The $T_{c}$ profile displayed in Fig. 2(b) turns out to be a strongly non-linear function of the laser intensity. The profiles obtained at $I \sim 3.2 \times 10^{18} \mathrm{~W} / \mathrm{cm}^{2}$ and at $I \sim 1.6 \times 10^{18} \mathrm{~W} / \mathrm{cm}^{2}$ almost coincide (to within $\sim 20 \%$ ) up to $R=14 \mu \mathrm{m}$, whereas the peak temperature reached at $I \sim 8 \times 10^{17} \mathrm{~W} / \mathrm{cm}^{2}$ is lower than the value obtained at $\sim 1.6 \times 10^{18} \mathrm{~W} / \mathrm{cm}^{2}$ by a factor $\sim 13$. By contrast, in the range $1.2 \times 10^{19} \mathrm{Wcm}^{-2}<I<5 \times 10^{19} \mathrm{Wcm}^{-2}$ associated to a $320 \mathrm{fs}$ pulse, the $T_{c}$ profiles exhibit an almost linear dependence upon the intensity at various radial positions (Figure 3(b)). In accordance with previous experiments in similar conditions, we find that $T_{c}$ scales as $\sim 1-2 \mathrm{eV} / \mathrm{J}$ of laser energy. ${ }^{23-26}$ Similar to the case with $\tau=5 \mathrm{ps}$, for $\tau=320$ we find a bell-shaped $n_{h}$ profile (Figure 3(a)).

The variations of the $n_{c}$ and $T_{c}$ profiles against the target thickness (in the range $9.4 \mu \mathrm{m}-25 \mu \mathrm{m}$ ) are displayed in Figures 4(a) and 4(b). We find that the peak value of $T_{c}$ approximately scales as the inverse of the thickness (Fig. 4(b)). For the $9.4 \mu \mathrm{m}$-target, temperatures of a few eV can be measured up to radial distances of $\sim 135 \mu \mathrm{m}$. For thicker targets, the heating drops below the detection limit beyond $\sim 60-80 \mu \mathrm{m}$.

To gain insight into these results, we now consider in more detail the energy dissipation channels between the hot electrons and the bulk target particles. To this goal, we work out a simple three-temperature model that generalizes the work of Ref. 28.

\section{MODELING}

Our model consists of solving the coupled heat equations of the hot electrons, bulk (cold) electrons, and ions. The energy source provided by the hot electrons is transferred to the bulk plasmas through three main channels: (i) direct collisions with the target bulk electrons; (ii) adiabatic cooling due to plasma expansion (as a result of the ambipolar field driving the target ions); (iii) electric slowing down due to the finite target resistivity. The energy distribution of the hot electron is taken in the form $f(E)=\exp \left(-E / T_{h}\right)$. In
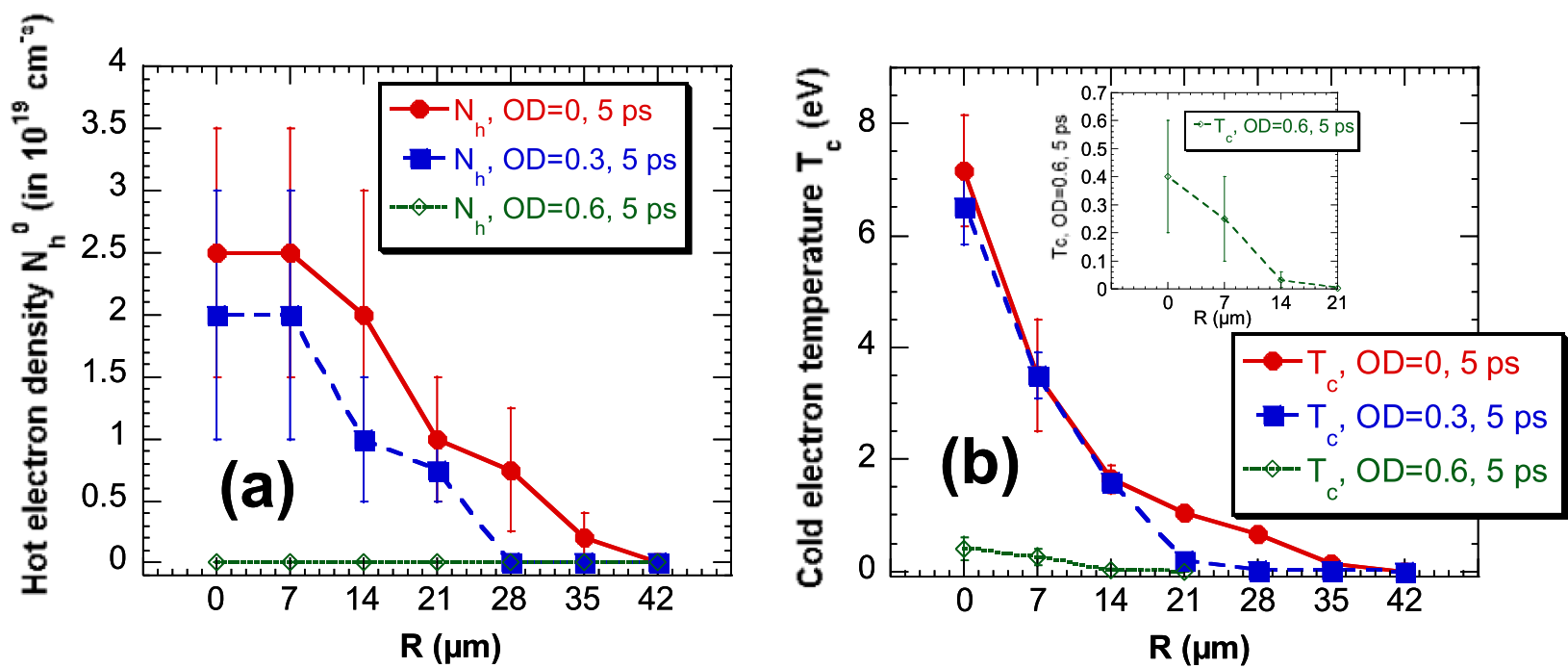

FIG. 2. (a) Spatial profile of the hot electron density for a $25 \mu \mathrm{m}$ thick Al target irradiated with pulse duration $\tau=5 \mathrm{ps}$ and intensity $\mathrm{I} \sim 3.2 \times 10^{18} \mathrm{~W} / \mathrm{cm}^{2}$ (dots), I $\sim 1.6 \times 10^{18} \mathrm{~W} / \mathrm{cm}^{2}$ (squares), and $\mathrm{I} \sim 8 \times 10^{17} \mathrm{~W} / \mathrm{cm}^{2}$ (diamonds). (b) Corresponding profiles of the bulk electron temperature. The inset is a detail of the cold electron temperature for the shot performed at $\mathrm{I} \sim 8 \times 10^{17} \mathrm{~W} / \mathrm{cm}^{2}$ (diamonds). The inferred average hot electron temperature is $\mathrm{T}_{\mathrm{h}}^{0}=0.45 \mathrm{MeV}$. 

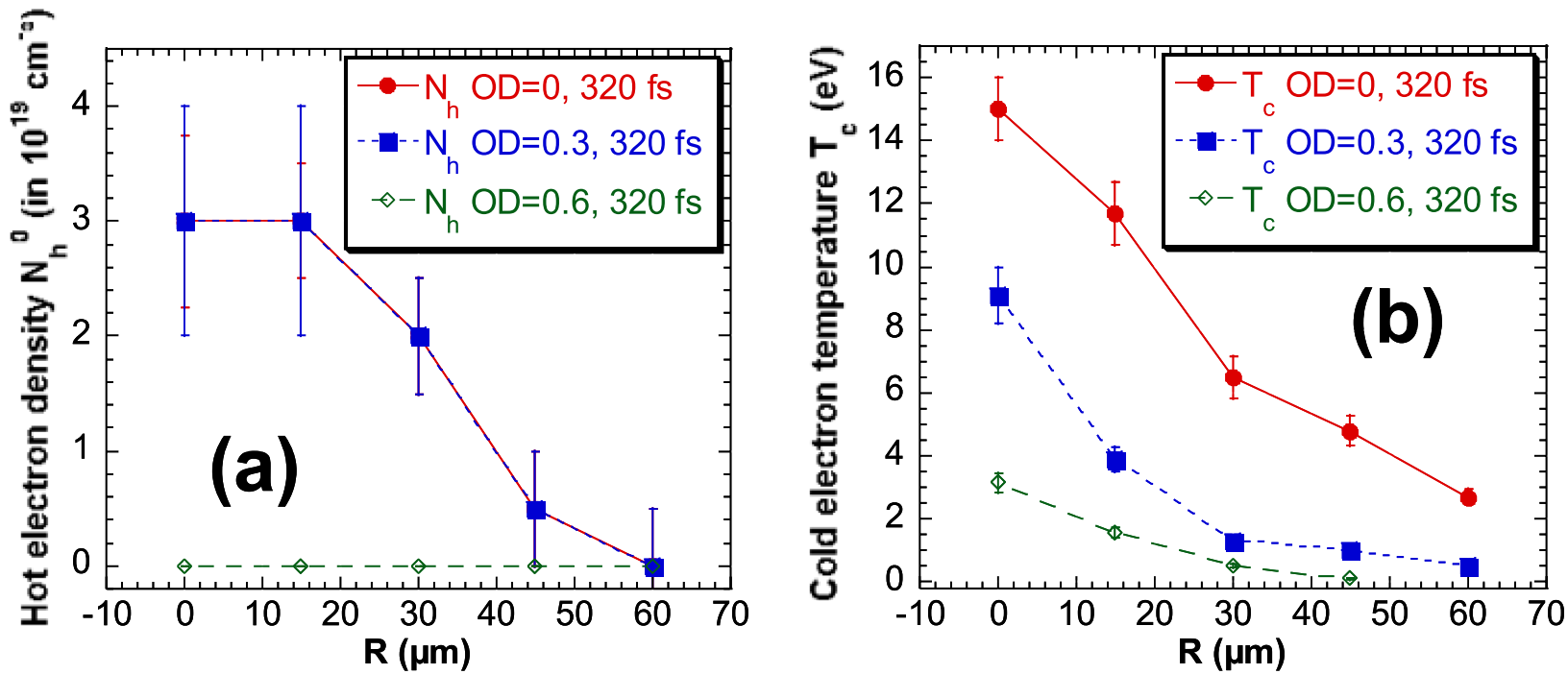

FIG. 3. (a) Spatial profile of the hot electron density for a $25 \mu$ m thick Al target irradiated with pulse duration $\tau=320 \mathrm{fs}$ at $\mathrm{I} \sim 5 \times 10^{19} \mathrm{~W} / \mathrm{cm}^{2}$ (dots), I $\sim$ $2.5 \times 10^{19} \mathrm{~W} / \mathrm{cm}^{2}$ (squares), and $\mathrm{I} \sim 1.2 \times 10^{19} \mathrm{~W} / \mathrm{cm}^{2}$ (diamonds). (b) Corresponding profiles of the bulk electron temperature. The inferred average hot electron temperature is $\mathrm{T}_{\mathrm{h}}{ }^{0}=0.45 \mathrm{MeV}$ in the first two cases.

practice, the hot electrons are initially distributed in a number of energy groups (200, in our case) within the energy range $10 \mathrm{keV}<E<10 T_{h}$, with numerical weights $p_{i}$ given by

$$
p_{i}=\exp \left(-E_{i} / T_{h}\right) / \sum_{i=1}^{N} \exp \left(-E_{i} / T_{h}\right)
$$

According to the previous discussion, the energy equation for the hot electrons thus writes

$$
\frac{d E_{h_{i}}}{d t}=\frac{L_{c}(t)}{L_{h}(t)} S_{h c}\left(E_{h_{i}}, n_{c}, Z^{*}\right) v_{h_{i}}+\left.\frac{d E_{h_{i}}}{d x}\right|_{a d}-\frac{L_{c}(t)}{L_{h}(t)} \frac{\eta\left(T_{c}\right) j_{h}^{2}}{n_{h}}
$$

Here, $E_{h_{i}}$ [similar to what indicated in formula (5)] is the hot electron energy of each energy bin, $L_{c}(t)$ and $L_{h}(t)$ the spatial extents of the cold and hot electron population, $S_{h c}$ is the stopping power due to bound and free electrons, as well as to plasmons, ${ }^{29} v_{h_{i}}$ is the velocity of the electrons related to its bin, $\eta\left(T_{c}\right)$ is the target resistivity ${ }^{30}$ and $j_{h}$ is the hot electron current density. The right-hand term in Eq. (5) accounts for the slowing down induced by the resistive field $E \sim \eta j_{h}$. The hot electron current density can be estimated from $j_{h} \tau=e n_{h} L_{0}$, with $\tau$ the laser duration, $e$ the electron charge and $L_{0}$ the initial target thickness. Once the hot electrons start recirculating through the target, we expect their net current and the associated resistive heating to drop significantly. In practice, $j_{h}$ is thus assumed to vanish for times larger than the average transit time of the hot electrons through the target.

The targets under consideration have a thickness of the order of a few microns, which is much smaller than their mmsize longitudinal dimension. As a result, their expansion can be reasonably assumed one-dimensional along the longitudinal direction. The hot electron expansion can be characterized by the time-dependent effective size $L_{h}(t)$ and density $n_{h}(t)$,
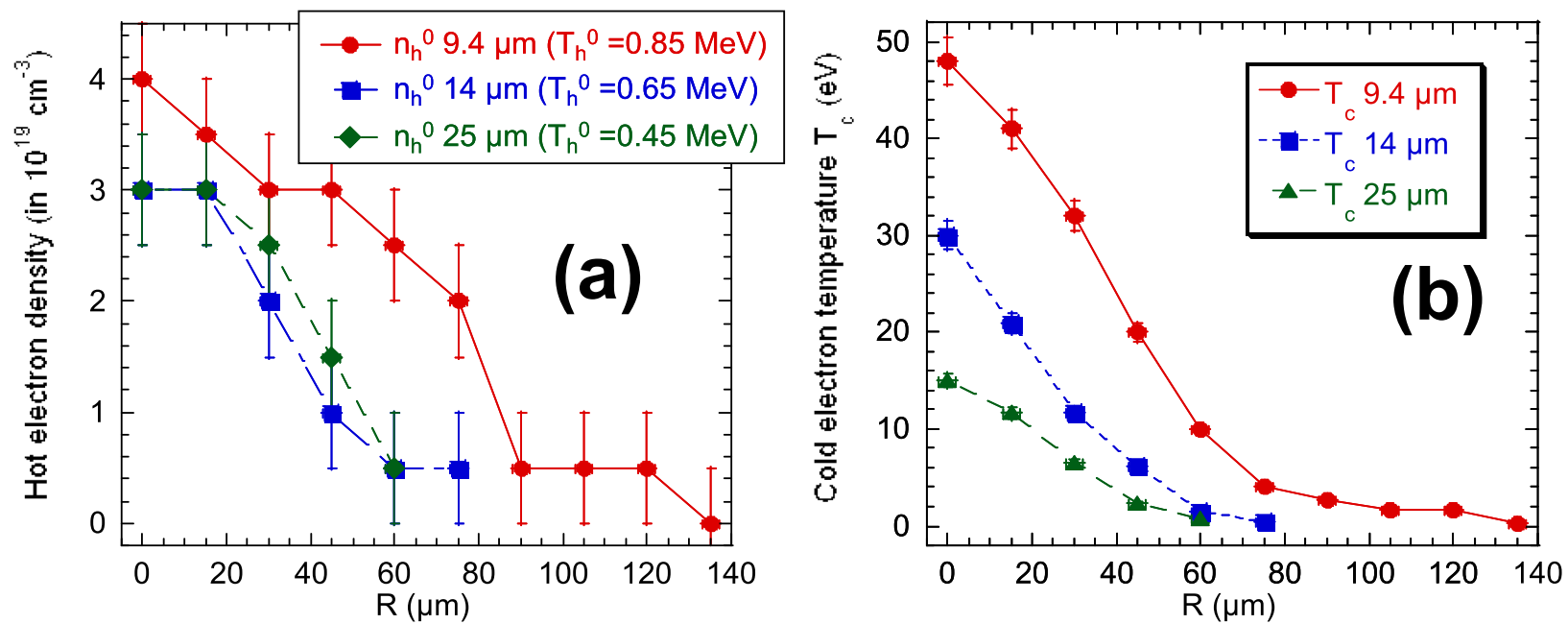

FIG. 4. (a) Spatial profile of the hot electron density for three Al target thicknesses at fixed laser intensity $\sim 5 \times 10^{19} \mathrm{~W} / \mathrm{cm}^{2}$ and pulse duration $\tau=320 \mathrm{fs}$. The average hot electron temperature $\mathrm{T}_{\mathrm{h}}{ }^{0}$ is also indicated and is found to agree with the scalings suggested by Ref. 27 for similar target thicknesses $(\sim 10 \mu \mathrm{m})$. (b) Corresponding profiles of the bulk electron temperature. 
which are related through the equation $n_{h}(t)=n_{h 0} L_{0} / L_{h}(t)$, where $n_{h 0}=n_{h}(0)$ and $L_{h 0}=l_{h}(0)$ are the initial hot electron density and target thickness, respectively. The ratio $L_{c} / L_{h}$ that multiplies the stopping power and resistive terms in Eq. (5) measures the reduction of the energy transfer caused by the hot electrons' expanding on distances larger than the bulk target size. This expansion entails the adiabatic cooling of the hot electrons according to $P V^{\Upsilon}=$ const. The 1D expansion implies $\Upsilon=3$ and $V=L$, there follows, for Eq. (5):

$$
\left.\frac{d E_{h_{i}}}{d x}\right|_{a d}=-2 \frac{E_{h_{i}}}{L_{h}(t)} \frac{d L_{h}(t)}{d t} .
$$

In order to determine the evolution of $L_{h}(t)$, we assume that the hot electron density within the target significantly departs from its initial value only after the rarefaction waves, generated at the target border, have reached the center. ${ }^{31}$ If we define $\Delta x_{r h}$ the distance covered by the rarefaction wave, this occurs when

$$
\Delta x_{r h}(t)=\int_{0}^{t} c_{s h}\left(t^{\prime}\right) d t^{\prime}=L_{0} / 2,
$$

where

$$
c_{s h}(t)=\sqrt{Z^{*}(t)\left\langle E_{h}\right\rangle / m_{i}},
$$

is the sound velocity associated to the hot electron expansion. $^{32}$ To define it, we have introduced the mean temperature for the hot electrons

$$
\left\langle E_{h}\right\rangle=\sum_{i} p_{i} E_{h_{i}}(t)
$$

The density is kept unchanged $\left(n_{h}(t)=n_{h 0}\right)$ as long as $\Delta x_{r h} \leq L_{0} / 2$. For $\Delta x_{r h} \geq L_{0} / 2$, we assume a self-similar expansion ruled by the equation ${ }^{33}$

$$
\frac{d^{2} L_{h}^{2}}{d t^{2}}=2 c_{s h}^{2}(t) .
$$

The hot electrons transfer their energy to the cold electrons, which, at a slower rate, transfer part of their energy to the ions. We can therefore write for the bulk electrons and ions

$$
\begin{aligned}
C_{e} \frac{d T_{c}}{d t}= & n_{h} \sum_{i=1}^{N} p_{i} \prod\left(E_{i}\right) v_{i}-c_{e i}\left(T_{c}-T_{i}\right) \\
& +\eta\left(T_{c}\right) j_{h}^{2} / C_{e}+\left.C_{e} \frac{d T_{c}}{d t}\right|_{a d}-Q_{r}, \\
C_{i} \frac{d T_{i}}{d t} & =c_{e i}\left(T_{c}-T_{i}\right)+\left.C_{i}\left(T_{i}\right) \frac{d T_{i}}{d t}\right|_{a d}
\end{aligned}
$$

where $C_{i}$ and $C_{e}$ are the bulk ion and electron heat capacities, $c_{e i}$ is the coupling coefficient and $Q_{r}$ is the radiative power loss per unit volume (see later). The bulk target particles obey the same expansion model than that used for the hot electrons

$$
\left.\frac{d T_{i, c}}{d t}\right|_{a d}=-2 \frac{T_{i, c}}{L_{c}} \frac{d L_{c}}{d t},
$$

$$
\frac{d^{2} L_{c}}{d t^{2}}=2 C_{s c}^{2}(t) \text { for } \Delta \mathrm{x}_{\mathrm{rc}}>\mathrm{L}_{0} / 2 \text { and } 0 \text { for } \Delta \mathrm{x}_{\mathrm{rc}} \leq \mathrm{L}_{0} / 2 \text {, }
$$

with

$$
c_{s h}(t)=\sqrt{Z^{*}(t) T_{c} / m_{i}} \quad \text { and } \quad x_{r c} / d t=c_{s c}(t) .
$$

Since the ions of interest for the TASRI diagnostic are those pertaining to the dense and cold part of the target, we have assumed $L_{i}=L_{C}$.

The electron heat capacity $C_{e}$ is calculated as in Ref. 34

$$
C_{e}=\frac{1}{\sqrt{\frac{1}{C_{e 1}^{2}}+\frac{1}{C_{e 2}^{2}}}},
$$

where $C_{e 1}$ is the electron heat capacity for a degenerate plasma, which writes

$$
C_{e 1}=\frac{1}{2} \pi^{2} n_{c} k_{b} \frac{T_{c}}{T_{f}},
$$

and $C_{e 2}$ is the electron heat capacity for a Maxwellian plasma

$$
C_{e 2}=\frac{3}{2} n_{c} k_{b},
$$

with $n_{e}=Z^{*} n_{i}$. The ionization degree $Z^{*}$ is calculated using the Thomas-Fermi model. ${ }^{35}$ We have checked that the simple interpolation formula Eq. (16) satisfactorily reproduces the SESAME data used in Ref. 36.

As for the ions, the ion heat capacity can be conveniently expressed as ${ }^{37}$

$$
C_{i}=3 n_{i} k_{B} \quad \text { for } \quad \mathrm{T}<\mathrm{T}_{\mathrm{m}},
$$

where $T_{m}$ is the melting temperature and

$$
C_{i}=\frac{3}{2} n_{i} k_{b}\left[1+\frac{2}{3}\left(\frac{T_{m}}{T_{i}}\right)^{1 / 3}\right] \text { for } T>T_{m} .
$$

Although quite simple, the above formulae closely agree with the corresponding SESAME values ${ }^{36}$ used in hydrodynamic simulations for non-equilibrium plasmas. ${ }^{34}$

The electron-to-ion energy transfer is governed by the coupling coefficient $c_{e i}$. Below the melting point, we can approximate $C_{e i} \approx c_{e i 0} \approx 3 \times 10^{17} \mathrm{Wcm}^{-3} \mathrm{~K}$ for aluminum and copper $^{38,39}$ and approximate $C_{e i} \approx c_{e i 0} \approx(2-3)$ $\times 10^{16} \mathrm{Wcm}^{-3} \mathrm{~K}$ for gold. ${ }^{36}$ To cover the temperature range of interest, we use the rough approximation $c_{e i}=\min \left(c_{e i 0}, c_{e i s}\right)$, where $c_{e i s}$ is the ideal plasma (Spitzer $^{40}$ formula covering classical and degenerate plasma regimes $^{41}$

$$
C_{e i s}=\frac{1}{3(2 \pi)^{3 / 2}} \frac{Z n_{e} e^{4} \operatorname{In} \Lambda}{\varepsilon_{0}^{2} m_{e}^{1 / 2}\left(k_{b} T_{e}\right)^{3 / 2}} .
$$

The factor $Q_{r}$ quantifies the radiative losses (relevant only at temperatures $>1 \mathrm{keV}$ ). The opaque and transparent plasma regimes are treated by the following formula: ${ }^{42}$ 

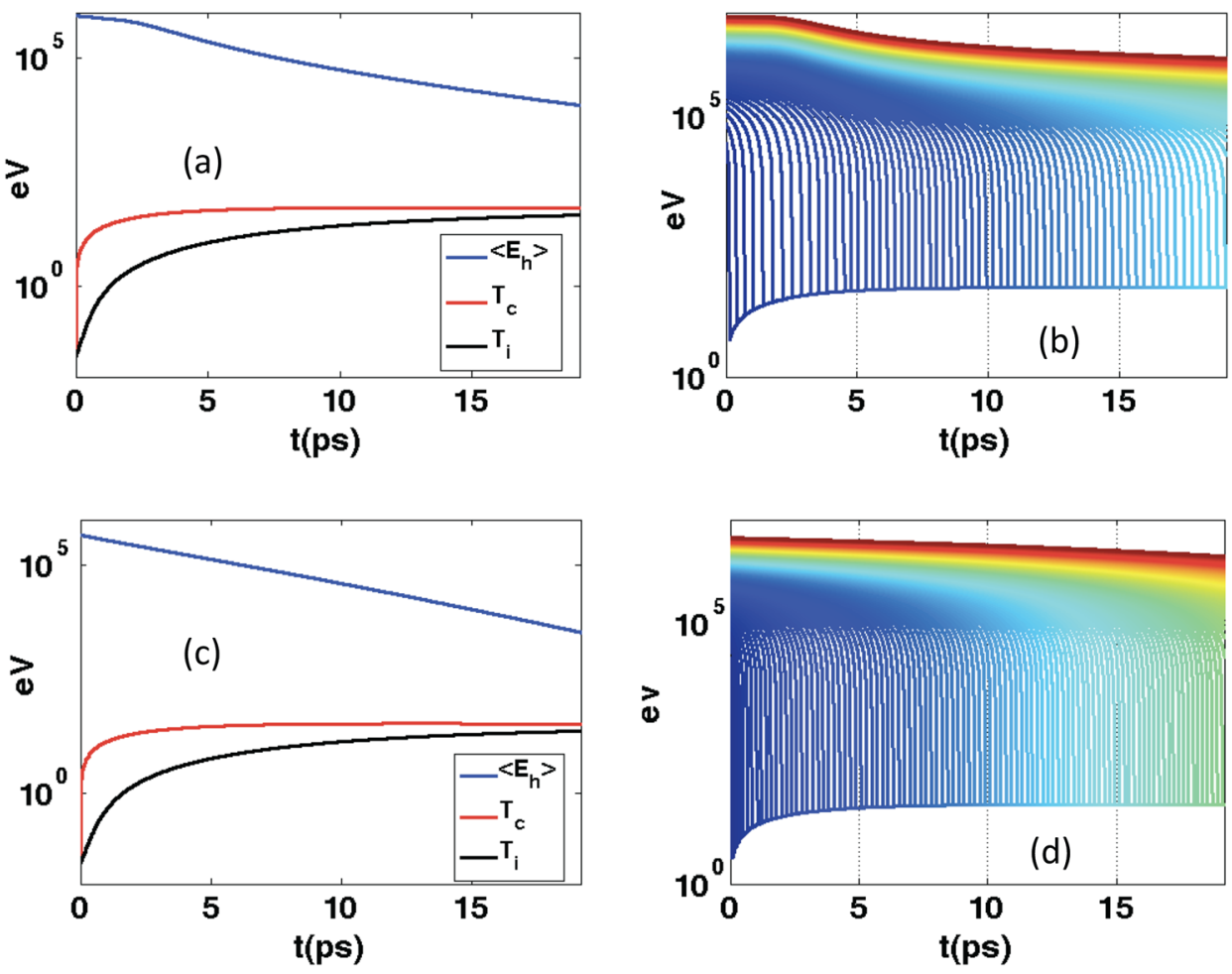

FIG. 5. Simulated time evolution of the average hot electron energy and bulk Al target temperatures (left) and of the various hot electron energy groups (right) for two sets of input parameters: $\quad \mathrm{n}_{\mathrm{h}}=2.5 \times 10^{19} \mathrm{~cm}^{-3}$, $\mathrm{T}_{\mathrm{h}}=0.45 \mathrm{MeV}, \quad \mathrm{L}_{0}=25 \mu \mathrm{m} \quad$ (top); $\mathrm{n}_{\mathrm{h}}=4 \times 10^{19} \mathrm{~cm}^{-3}, \quad \mathrm{~T}_{\mathrm{h}}=0.85 \mathrm{MeV}$ and $\mathrm{L}_{0}=9.4 \mu \mathrm{m}$ (bottom). In both cases the pulse length is $320 \mathrm{fs}$.

$$
Q_{r}=\frac{Q_{B} Q_{B B}}{Q_{B}+Q_{B B}}
$$

where the Bremsstrahlung-radiation $\left(Q_{B}\right)$ and the blackbody radiation $\left(Q_{B B}\right)$ terms can be expressed as

$$
\begin{aligned}
Q_{B}\left[W m^{-3}\right] & =\frac{Z^{* 2} n_{c} n_{i} T_{e}[e V]^{1 / 2}}{\left(7.69 \times 10^{18} m^{-3}\right)} \\
Q_{B B}\left[W m^{-3}\right] & =\frac{\sigma T_{C}^{4}}{L_{C}}
\end{aligned}
$$

with $\sigma$ is the Planck constant.

Figure 5 shows the time evolution of the averaged hot electron energy $\left\langle E_{h}\right\rangle$ and the bulk temperatures $T_{c}$ and $T_{i}$ as obtained from numerically solving the above system of equations using as input the TASRI-inferred parameters: $T_{h}=0.45 \mathrm{MeV}, n_{h}=2.5 \times 10^{19} \mathrm{~cm}^{-3}$, and $T_{c}=T_{i}=300 \mathrm{~K}$ for the $25 \mu \mathrm{m}$ target; $T_{h}=0.85 \mathrm{MeV}, n_{h}=4 \times 10^{19} \mathrm{~cm}^{-3}$, and $T_{c}=T_{i}=300 \mathrm{~K}$ for the $9.4 \mu \mathrm{m}$ target. Let us now compare the simulated $T_{c}$ values to the measurements in order to benchmark our code, and the domain of parameters where it would be valid. We see that $T_{c}$ saturates quite quickly while $\left\langle E_{h}\right\rangle$ decreases on a longer timescale. The late-time behavior of $\mathrm{T}_{\mathrm{c}}, \mathrm{T}_{\mathrm{i}},\left\langle\mathrm{E}_{\mathrm{h}}\right\rangle$ as displayed in Figure 5 can be easily understood. At the end of the computation, $\left\langle E_{h}\right\rangle$ (i.e. the mean individual energy of the hot electrons) remains still higher than $T_{c}$, suggesting a continuation of energy transfer. However, the energy transfer rate decreases since the hot electron energy density $\left(\sim n_{h}\left\langle E_{h}\right\rangle\right)$ has then become negligible related to the thermal energy density of the plasma $\left(\sim n_{c} T_{c}\right)$. As a consequence, the energy transfer to the ions decreases, generating the observed saturation effect of $T_{c}$. At later times, $T_{c}$ even diminishes owing to the prevailing energy transfer to the ions.
The maximum target temperatures predicted for the three target thicknesses considered $(9.4,14,25 \mu \mathrm{m})$ are, respectively, $T_{c}=51,43$, and $32 \mathrm{eV}$. Overall, these values compare reasonably well to those inferred from the TASRI data, namely $T_{c}=48,31$ and $15 \mathrm{eV}$. The discrepancy observed for the thickest targets can be attributed to the fact that lateral expansion effects then become more pronounced, hence weakening the target heating. Despite its shortcomings, our 0-D model provides a satisfactory description of the target heating as a function of the hot electron source.

Additional calculations have been performed to assess the dependence of the maximum value of $T_{c}$ upon $T_{h}$ and $n_{h}$. We have found that $T_{c}$ is much more sensitive to $n_{h}$ than to $T_{h}$ : increasing $T_{h}$ by a factor of 2 , i.e., from 0.45 to $0.9 \mathrm{MeV}$, only marginally increases $T_{c}$ by less than $10 \%$ whereas dividing $n_{h}$ by a factor of 2 (i.e., $n_{h}=1.4 \times 10^{19} \mathrm{~cm}^{-3}$ ) almost halves the peak value of $T_{c}$. We therefore deduce that the electron density at the rear target surface has a very strong contribution to bulk heating, in agreement with the results of Figure 2. The importance of a confined hot electron distribution for enhancing the acceleration process has already been confirmed by various experiments based on mass-limited targets. ${ }^{43}$ The present model also indicates that, for the parameters investigated here, the return current term weakly contributes $(<10 \%)$ to the final target temperature. The code therefore allows us to estimate the interplay between the different parameters involved in the acceleration process, namely the hot electron temperature, density, and return current and gives us insight about their dependencies.

\section{CONCLUSIONS}

The properties of the bulk and hot electron populations at the rear side of a laser-irradiated micrometer solid targets 
have been inferred from a time- and space-resolved diagnostic for laser intensities ranging from $10^{18} \mathrm{~W} / \mathrm{cm}^{2}$ to $5 \times 10^{19} \mathrm{~W} / \mathrm{cm}^{2}$. These measurements are satisfactorily reproduced by a simple three-temperature model, which further shows that, in our typical parameter range, the target heating is mainly determined by the hot electron density. Our model also indicates that, for the relatively weak rear-side hot electron density under consideration, the return current plays only a minor role in the target heating.

\section{ACKNOWLEDGMENTS}

We acknowledge the expert support of the LULI laser team and the help and useful discussions with J. P. Geindre. This work was supported by Marie Curie Actions, DAAD, British Council/Egide/Alliance, Grant No. E1127 from Région Ile-de-France, the EU Program No. HPRI CT 19990052, TR No. 18 and GK No. 1203 funding, ANR-06BLAN-0392 from ANR-France, SPARX-MIUR (Contract No. RBAP06AHF8_002) and CRISP (FP7 Contract No. 283745) supported by FRQNT (nouveaux chercheurs, Grant No. 174726) and an NSERC Discovery Grant (Grant No. 435416).

${ }^{1}$ F. Floux, D. Cognard, L.-G. Denoeud, G. Piar, D. Parisot, J. M. Bobin, F. Delobeau, and C. Fauquignon, Phys. Rev. A 1, 821 (1970).

${ }^{2}$ M. Tabak, J. Hammer, M. E. Glinsky, W. L. Kruer, S. C. Wilks, J. Woodworth, E. M. Campbell, M. D. Perry, and R. J. Mason, Phys. Plasmas 1(5), 1626-1634 (1994).

${ }^{3}$ M. Roth, T. E. Cowan, M. H. Key, S. P. Hatchett, C. Brown, W. Fountain, J. Johnson, D. M. Pennington, R. A. Snavely, S. C. Wilks, K. Yasuike, H. Ruhl, F. Pegoraro, S. V. Bulanov, E. M. Campbell, M. D. Perry, and H. Powell, Phys. Rev. Lett. 86, 436 (2001).

${ }^{4}$ L. Romagnani, J. Fuchs, M. Borghesi, P. Antici, P. Audebert, F. Ceccherini, T. Cowan, T. Grismayer, S. Kar, A. Macchi, P. Mora, G. Pretzler, A. Schiavi, T. Toncian, and O. Willi, Phys. Rev. Lett. 95, 195001 (2005).

${ }^{5}$ T. Toncian, M. Borghesi, J. Fuchs, E. d'Humières, P. Antici, P. Audebert, E. Brambrink, C. A. Cecchetti, A. Pipahl, L. Romagnani, and O. Willi, Science 312, 410 (2006); O. Willi, T. Toncian, M. Borghesi, J. Fuchs, E. d'Humières, P. Antici, P. Audebert, E. Brambrink, C. Cecchetti, A. Pipahl, and L. Romagnani, Laser Part. Beams 25(1), 71 (2007).

${ }^{6}$ P. Antici, A. Bacci, C. Benedetti, E. Chiadroni, M. Ferrario, A. R. Rossi, L. Lancia, M. Migliorati, A. Mostacci, L. Palumbo, and L. Serafini, J. Appl. Phys. 112, 044902 (2012).

${ }^{7}$ P. Antici, M. Fazi, A. Lombardi, M. Migliorati, L. Palumbo, P. Audebert, and J. Fuchs, J. Appl. Phys. 104, 124901 (2008).

${ }^{8}$ K. Patel, A. J. Mackinnon, M. H. Key, T. E. Cowan, M. E. Foord, M. Allen, D. F. Price, H. Ruhl, P. T. Springer, and R. Stephens, Phys. Rev. Lett. 91, 125004 (2003).

${ }^{9}$ A. Mancic, J. Robiche, P. Antici, P. Audebert, C. Blancard, P. Combis, F. Dorchies, G. Faussurier, S. Fourmaux, M. Harmand, R. Kodama, L. Lancia, S. Mazevet, M. Nakatsutsumi, O. Peyrusse, V. Recoules, P. Renaudin, R. Shepherd, and J. Fuchs, High Energy Density Phys. 6(1), 21 (2010); A. Mancic, A. Levy, M. Harmand, M. Nakatsutsumi, P. Antici, P. Audebert, P. Combis, S. Fourmaux, S. Mazevet, O. Peyrusse, V. Recoules, P. Renaudin, J. Robiche, F. Dorchies, and J. Fuchs, Phys. Rev. Lett. 104, 035002 (2010).

${ }^{10}$ P. Antici, J. Fuchs, S. Atzeni, A. Benuzzi, E. Brambrink, M. Esposito, M. Koenig, A. Ravasio, J. Schreiber, A. Schiavi, and P. Audebert, J. Phys. (France) 133, 1077 (2006).

${ }^{11}$ S. Ichimaru, Rev. Mod. Phys. 54, 1017 (1982).

${ }^{12}$ F. Perez, L. Gremillet, M. Koenig, S. D. Baton, P. Audebert, M. Chahid, C. Rousseaux, M. Drouin, E. Lefebvre, T. Vinci, J. Rassuchine, T. Cowan, S. A. Gaillard, K. A. Flippo, and R. Shepherd, Phys. Rev. Lett. 104, 085001 (2010).
${ }^{13}$ A. J. Mackinnon, Y. Sentoku, P. K. Patel, D. W. Price, S. Hatchett, M. H. Key, C. Andersen, R. Snavely, and R. R. Freeman, Phys. Rev. Lett. 88, 215006 (2002).

${ }^{14}$ S. N. Chen, G. Gregori, P. K. Patel, H.-K. Chung, R. G. Evans, R. R. Freeman, E. G. Saiz, S. H. Glenzer, S. B. Hansen, F. Y. Khattak, J. A. King, A. J. Mackinnon, M. M. Notley, J. R. Pasley, D. Riley, R. B. Stephens, R. L. Weber, S. C. Wilks, and F. N. Beg, Phys. Plasmas 14, 102701 (2007).

${ }^{15}$ K. U. Akli, S. B. Hansen, A. J. Kemp, R. R. Freeman, F. N. Beg, D. C. Clark, S. D. Chen, D. Hey, S. P. Hatchett, K. Highbarger, E. Giraldez, J. S. Green, G. Gregori, K. L. Lancaster, T. Ma, A. J. MacKinnon, P. Norreys, N. Patel, J. Pasley, C. Shearer, R. B. Stephens, C. Stoeckl, M. Storm, W. Theobald, L. D. Van Woerkom, R. Weber, and M. H. Key, Phys. Rev. Lett. 100, 165002 (2008).

${ }^{16}$ M. Nakatsutsumi, J. R. Davies, R. Kodama, J. S. Green, K. L. Lancaster, K. U. Akli, F. N. Beg, S. N. Chen, D. Clark, R. R. Freeman, C. D. Gregory, H. Habara, R. Heathcote, D. S. Hey, K. Highbarger, P. Jaanimagi, M. H. Key, K. Krushelnick, T. Ma, A. MacPhee, A. J. MacKinnon, H. Nakamura, R. B. Stephens, M. Storm, M. Tampo, W. Theobald, L. Van Woerkom, R. L. Weber, M. S. Wei, N. C. Woolsey, and P. A. Norreys, New J. Phys. 10, 043046 (2008).

${ }^{17}$ P. Audebert, V. Nagels, J. P. Geindre, F. Dorchies, O. Peyrusse, S. Gary, F. Girard, R. Shepherd, J. C. Gauthier, and C. Chenais-Popovics, J. Quant. Spectrosc. Radiat. Transf. 81, 19-30 (2003).

${ }^{18}$ L. A. Gizzi, A. Giulietti, and O. Willi, J. X-Ray Sci. Technol. 7, 186 (1997).

${ }^{19}$ S. N. Chen, P. K. Patel, H.-K. Chung, A. J. Kemp, S. Le Pape, B. R. Maddox, S. C. Wilks, R. B. Stephens, and F. N. Beg, Phys. Plasmas 16, 062701 (2009).

${ }^{20}$ P. Antici, S. N. Chen, L. Gremillet, T. Grismayer, P. Mora, P. Audebert, and J. Fuchs, Rev. Sci. Instrum. 81, 113302 (2010).

${ }^{21}$ P. Antici, J. Fuchs, M. Borghesi, L. Gremillet, T. Grismayer, Y. Sentoku, E. d'Humières, C. A. Cecchetti, A. Mancic, A. C. Pipahl, O. Willi, P. Mora, and P. Audebert, Phys. Rev. Lett. 101, 105004 (2008).

${ }^{22}$ B. Wattellier, J. Fuchs, J. P. Zou, K. Abdeli, H. Pepin, and C. Haefner, Opt. Lett. 29, 2494-2496 (2004).

${ }^{23}$ R. G. Evans, E. L. Clark, R. T. Eagleton, A. M. Dunne, R. D. Edwards, W. J. Garbett, T. J. Goldsack, S. James, C. C. Smith, B. R. Thomas, R. Clarke, D. J. Neely, and S. J. Rose, Appl. Phys. Lett. 86, 191505 (2005).

${ }^{24}$ J. A. Koch, M. H. Key, R. R. Freeman, S. P. Hatchett, R. W. Lee, D. Pennington, R. B. Stephens, and M. Tabak, Phys. Rev. E 65, 016410 (2001).

${ }^{25}$ M. Borghesi, J. Fuchs, S. V. Bulanov, A. J. Mackinnon, P. K. Patel, and M. Roth, Fusion Sci. Technol. 49, $412-439$ (2006); see http://www.ans.org/ pubs/journals/fst/a_1159.

${ }^{26}$ H. Popescu, S. D. Baton, F. Amiranoff, C. Rousseaux, M. Rabec Le Gloahec, J. J. Santos, L. Gremillet, M. Koenig, E. Martinolli, T. Hall, J. C. Adam, A. Heron, and D. Batani, Phys. Plasmas 12, 063106 (2005).

${ }^{27}$ F. N. Beg, A. R. Bell, A. E. Dangor, C. N. Danson, A. P. Fews, M. E. Glinsky, B. A. Hammel, P. Lee, P. A. Norreys, and M. Tatarakis, Phys. Plasmas 4, 447 (1997).

${ }^{28}$ A. Kemp, J. Fuchs, Y. Sentoku, V. Sotnikov, M. Bakeman, P. Antici, and T. Cowan, Phys. Rev. E 75, 056401 (2007).

${ }^{29}$ V. V. Val'Chuk, N. B. Volkov, and P. A. Yalovets, Plasma Phys. Rep. 21, 159 (1995).

${ }^{30}$ Y. T. Lee and R. M. More, Phys. Fluids 27, 1273 (1984).

${ }^{31}$ P. Mora, Phys. Rev. E 72(5), 056401 (2005).

${ }^{32}$ V. Y. Bychenkov, V. Novikov, D. Batani, V. Tikhonchuk, and S. G. Bochkarev, Phys. Plasmas 11, 3242 (2004).

${ }^{33}$ D. S. Dorozhkina and V. E. Semenov, Phys. Rev. Lett. 81(13), 2691 (1998).

${ }^{34}$ D. Fisher, M. Fraenkel, Z. Henis, E. Moshe, and S. Eliezer, Phys. Rev. E 65, 016409 (2001).

${ }^{35}$ R. M. More, Atomic and Molecular Physics of Controlled Thermonuclear Fusion, edited by C. J. Joachain and D. E. Post (Plenum Publishing Corporation, 1983), pp. 399-439.

${ }^{36}$ K. Eidmann, J. Meyer-ter-Vehn, and T. Schlegel, Phys. Rev. E 62, 01202 (2000).

${ }^{37}$ R. M. More, K. H. Warren, D. A. Young, and G. B. Zimmerman, Phys. Fluids 31, 3059 (1988).

${ }^{38}$ B. Rethfeld, A. Kaiser, M. Vicanek, and G. Simon, Phys. Rev. B 65, 214303 (2002).

${ }^{39}$ B. J. Siwick, J. R. Dwyer, R. E. Jordan, and R. J. D. Miller, Science 302, 1382 (2003).

${ }^{40}$ L. Spitzer, Physics of Fully Ionized Gases (Wiley, New York, 1962). 
${ }^{41}$ H. Brysk, Phys. Plasmas 16, 927 (1974).

${ }^{42}$ S. Atzeni, Phys. Plasmas 6, 3316 (1999).

${ }^{43}$ S. Buffechoux, M. Nakatsutsumi, A. Andreev, K. Zeil, T. Burris, G. Sarri, M. Amin, P. Antici, T. Burris-Mog, A. Compant-La-Fontaine, E. d'Humières,
S. Fourmaux, S. Gaillard, F. Gobet, F. Hannachi, S. Kraft, A. Mancic, C. Plaisir, G. Sarri, M. Tarisien, T. Toncian, U. Schramm, M. Tampo, P. Audebert, O. Willi, T. E. Cowan, H. Pépin, V. Tikhonchuk, M. Borghesi, and J. Fuchs, Phys. Rev. Lett. 105, 015005 (2010). 